\title{
Lean Thinking \& People-oriented Management of State-owned Single Hotel_—A Case Study of Nanjing Huangpu Hotel
}

\author{
Ting Zhang ${ }^{\mathrm{a},}{ }^{*}$, Xinglin Chen ${ }^{\mathrm{b}}$ \\ School of Economic Management, Nanjing University of Science and Technology, Nanjing210094, \\ China \\ a classy528034@163.com, ${ }^{b}$ m15651800599@163.com
}

Keywords: State-owned hotel; Lean management; People-oriented management; Hotel management.

Abstract: As a typical service industry, the service of hotel is not only for customers, but also for employees. Only by serving good employees, employees will provide good services, and only satisfied employees can bring satisfactory customers. As an old state-owned hotel, Huangpu Hotel has never been fully renovated since its opening in 2003.

\section{Introduction}

Management is to put people first and strive for perfection. Huangpu Hotel combines the two advanced management concepts of lean management and people-oriented management to form lean \& people-oriented management. Starting from incentives, training, leadership, etc., they created a streamlined structure, accurate assessment, fine incentives, excellent training, sincere culture and refined actions to achieve the ultimate goal of joint development of organizations and individuals

\section{Lean Thinking \& People-oriented Management of Huangpu Hotel}

\subsection{Accurate assessment}

The assessment method of Huangpu Hotel can be summarized by sixteen words: "reverse profit, index decomposition, responsibility implementation, and linked assessment". This set of assessment methods has three main points:

History-based, future-oriented. The first thing to solve for the decomposition of profit indicators is the "distribution ratio". In this regard, Huangpu Hotel sets the profit grading indicators for performance appraisal based on historical data and analysis of future market potential. Historical data shows that a large part of the hotel's main business income comes from room revenue, so in the process of profit decomposition, the room will undoubtedly bear the bulk of the indicators. In 
addition, the hotel operation has obvious difference between the off-season seasons. From May to October each year, it is the tourist season in Nanjing. At this time, the demand for rooms and catering is much higher than usual. The hotel should seize the market opportunity and bear more in the peak season. Or according to the future conferences, exhibitions and other activities around the hotel to judge the potential market demand of the hotel, based on this, the profit indicators are more decomposed into the month of potential demand.

Equal emphasis on income and expenditure, Collaboration. The hotel not only has business departments that directly bring in operating income such as rooms and catering, but also personnel and administrative departments that cannot directly generate operating income. In the process of decomposing profit indicators, it is necessary to pay attention to the different assessment points of different departments. For example, assess the income or profit of the business department, while the functional department assesses the overall profit of the hotel and the direct costs of the department.

In addition, Huangpu Hotel adopts the profit decomposition method to assess the profit of the food and beverage department, while the sales department assesses the income, and skillfully avoids the disputes between the departments. Whether it's a guest room or a restaurant, the profits come from the customers brought by the sales department, and the sales department needs catering and rooms to provide good services to attract more customers and thus earn more income. In this way, the various departments are no longer a competitive relationship, but a community of destiny, a stakeholder, and ultimately form a joint operation to improve hotel performance.

Decentralization and authorization, reciprocity of power and responsibility. The Huangpu Hotel fully utilizes the decentralization and authorization, and adopts the method of profit reversal. The hotel decomposes the annual revenue and profit indicators into monthly and distributes them to the department. The hotel is mainly responsible for the assessment of the department level. The assessment of the employee level is completed by each department according to the actual situation. The same is true for the rewards after the completion of the assessment. The hotel will issue the bonus to the department, and the right to quantify the wage control will be given to the department. The department has the second distribution right to the bonus and salary. This kind of authorization not only greatly stimulates the department manager, but also plays a very important role in restraining employees.

It must be mentioned that the department manager of Huangpu Hotel does not take the departmental bonus, but the general manager's office evaluates the bonus according to other assessment methods, which largely eliminates the appearance of the department manager's power for personal gain. Such decentralization and authorization not only help to encourage department managers to work hard to improve hotel performance from all aspects, but also makes the general manager's management of the hotel not so small, and can have more time to think about the hotel's macro development strategy.

Through "profit reversal, index decomposition", the personal interests of employees are linked with the interests of the hotel, forming a good business atmosphere of "everyone pays attention to hotel benefits and actively reduce costs and increase efficiency”.

\subsection{Detailled excitation}

Based on the analysis of the turnover rate, Huangpu Hotel established an incentive mechanism for wages + bonuses and benefits to reduce the turnover rate, reduce employee turnover, and achieve sustainable development of the hotel.

Salary. In general, the salary of Huangpu Hotel consists of basic salary + performance + bonus, but employees at different levels have different assessment criteria and salary system. The management is mainly based on the group's indicators; the department manager is mainly based on the hotel's 
monthly indicators and the department's monthly profit and related cost indicators. The staff level is not only to assess the hotel's profits, but also according to the workload assessment, more work and more, It is also called the quantitative salary. Quantifying wages can effectively avoid the phenomenon of employees being lazy and "eat a big pot of rice", and it also greatly motivates employees' work enthusiasm and improves employee satisfaction.

Bonus. Huangpu Hotel has set up various reward mechanisms with various forms and different amounts, including basic prizes, standard awards, over-extensions, and assessment awards. In addition, the hotel also set up a personalized service award, designed to encourage employees to provide customers with "advance", "value", "surprise" personalized service, this award is mainly based on customer comments. And an innovation award that encourages employees to make rational recommendations for hotel management.

In addition, there are more than ten kinds of awards, such as various sales promotion methods, energy fee assessment and awarding methods, and special awards, which are not only "winning the prize" but also "rain and dew". Such a bonus system enables more people to work harder, which is conducive to the realization of benign and orderly competition within the hotel and the steady growth of the overall performance of the hotel.

Welfare. Relatively speaking, bonuses are only applicable to employees with high performance, but benefits are treated equally as a basic guarantee system. From the annual tour to the holiday gift card, birthday card, etc., Huangpu Hotel will provide care and help from the employees' personal interests, and will organize various activities to help employees establish intimacy. Friendly relationship. For new hires, the hotel also gives them the opportunity to enjoy the four-star dining and room service provided by the hotel for free.

\subsection{Excellent training}

Training is the guarantee for the hotel to obtain high-quality talents, and it is also an important source of hotel competitive advantage. The hotel not only needs to use people, but also educates people so that they can keep talented person.

So that Huangpu Hotel has established a comprehensive and comprehensive training system including training content, training methods and training implementation as well as training assessment. First of all, in terms of training content, the hotel has set up different training methods for different training targets. Secondly, as far as the training method is concerned, there are two kinds of expatriate training and on-the-job training. All the above-mentioned personnel of Huangpu Hotel are sent to the school or professional training institutions for about ten days of off-the-job training to help them learn more professional knowledge and better use theory to guide practice; in addition, the hotel will occasionally invite famous school teachers to provide on-the-job training for employees to enhance their professional skills and ideological qualities. Then, in terms of training implementation, Huangpu Hotel attaches great importance to staff training. In order to ensure the normal development of training, they have established hotel training specialists and trainers from various departments, and established organizational systems such as training and inspection systems and monthly training sessions for trainers to promote the implementation of training to an organizational level. Finally, in terms of training evaluation, the hotel has established a training file for each employee, and the trainer evaluates the training process and training results. The new employee induction training needs to be paid for.

In addition, Huangpu Hotel also adopts a multi-functional and cross-training method. Each department conducts cross-training of internal posts, so that each employee can learn as much business knowledge as possible and can bear more. This is a value added for the individual employee and a cost saving for the hotel. This not only saves labor costs, but also gives all departments the 
opportunity to contact customers and increase their understanding of customers, so as to provide better service to customers and ultimately achieve the purpose of improving hotel efficiency.

\subsection{Sincere culture}

The corporate culture of Huangpu Hotel can be summarized in the words "Dear and Sincerity". "Dear and sincerity" comes from Huangpu military academy. And it is the spiritual belief that the Huangpu Hotel has been pursuing. "Dear" means that you love each other and live in harmony. It also conveyed the beautiful vision of Huangpu Hotel, which hopes all employees can work together and live in harmony.

Huangpu Hotel always implements the corporate culture of "Dear and Sincerity", aiming at the improvement of overall efficiency, providing customers with meticulous and thoughtful service from the perspective of long-term development of the hotel, creating a harmonious and comfortable working environment for employees. Corporate culture focuses on understanding, and the key is implementation. Under the leadership of Manager Zhu, Huangpu Hotel combines corporate culture with specific management practices and implements all aspects of hotel management. First of all, create a good learning atmosphere, fully tap the enthusiasm and initiative of employees, and cultivate employees to learn and implement the hotel's corporate culture. For example, in the hotel, a freelance and speech contest with the theme of "customer satisfaction" is carried out. Well-written employees conduct public praise and publicity, and encourage employees to learn from each other; in addition, in order to enrich employees' cultural life, enhance team awareness, and create a harmonious and warm atmosphere, the hotel does not regularly hold badminton matches and job skills competitions, organized annually. Employees go out to travel, give employees birthdays and issue gift cards, so that employees can feel the collective warmth and care of the hotel.

\section{Conclusions}

As a typical service industry, the hotel faces the problems of serious staff turnover and high turnover rate. Huangpu Hotel has made breakthroughs in these problems through lean human management, and will strive to improve employee satisfaction throughout all aspects of human resource management. Business training to enhance employees' sense of accomplishment; to enhance employees' sense of honor with rich and colorful rewards; to enhance employees' sense of belonging with rich and colorful cultural activities; to enhance employees' happiness with increasing annual wages and benefits.

In this regard, other service companies can also learn from the successful experience of Huangpu Hotel, from the perspective of long-term development of the company, regard people as an important resource of the company, respect and understand the needs of employees, attach importance to employee development, and let employees pay If you can get a return, you can see hope through your efforts, so as to improve employee satisfaction and ultimately achieve long-term sustainable development.

\section{References}

[1] Vlachos I, Bogdanovic A. Lean thinking in the European hotel industry [J]. Tourism Management, 2013, 36(36):354-363.

[2] Lu S. The Application of People-Oriented Management Philosophy in Hotel Management [M]. Information and Business Intelligence. Springer Berlin Heidelberg, 2012:288-293.

[3] Thirkell E, Ashman I. Lean towards learning: connecting Lean Thinking and human resource management in UK higher education [J]. International Journal of Human Resource Management, 2014, 25(21):2957-2977.

[4] Sparrow P, Otayeebede L. Lean management and HR function capability: the role of HR architecture and the location 
of intellectual capital [J]. International Journal of Human Resource Management, 2014, 25(21):2892-2910.

Relations: A case study of Turkish hotel employees [J]. Journal of Human Resources in Hospitality \& Tourism, 2017(5):1-17.

[5] Ashton A S. How human resources management best practice influence employee satisfaction and job retention in the Thai hotel industry [J]. Journal of Human Resources in Hospitality \& Tourism, 2017(1):1-25.

[6] Zhang J. Analysis on Human Resource Management Based on the Lean Perspective [J]. Science \& Technology Management Research, 2010.

[7] Vlachos I, Bogdanovic A. Lean thinking in the European hotel industry [J]. Tourism Management, 2013, 36(36):354-363.

[8] Lu S. The Application of People-Oriented Management Philosophy in Hotel Management [M]. Information and Business Intelligence. Springer Berlin Heidelberg, 2012:288-293. 